This manuscript is a preprint that has been submitted to a peer-reviewed journal. The manuscript is yet to be reviewed, thus, subsequent versions of this manuscript may have different content. If accepted, the final version of this manuscript will be available via the 'Peer-reviewed Publication DOI' link. Please feel free to contact Dr Chris Yeomans (c.m.yeomans@exeter.ac.uk) to comment on the manuscript. We welcome feedback. 


\section{Highlights}

\section{Application of the tilt derivative transform to bathymetric data for structural lineament map- ping}

Christopher M. Yeomans, Matthew Head, Jordan J. Lindsay

- High-resolution bathymetric data are used to analyse submerged outcrops for structural lineaments

- Steps in bathymetry cause problems when enhancing lineaments using common feature extraction methods

- The tilt derivative transform successfully enhances lineaments prior to lineament extraction 


\title{
Application of the tilt derivative transform to bathymetric data for structural lineament mapping
}

\author{
Christopher M. Yeomans ${ }^{a, *}$, Matthew Head $^{a}$ and Jordan J. Lindsay ${ }^{a}$ \\ ${ }^{a}$ Camborne School of Mines, College of Engineering, Mathematics and Physical Sciences, University of Exeter, Penryn Campus, Penryn, \\ Cornwall, TR10 9FE, UK
}

\section{ARTICLE INFO}

\section{Keywords:}

Tilt derivative transform

Bathymetry

Lineament detection

Object-based Image Analysis

Southwest England

\begin{abstract}
A B S T R A C T
High-resolution bathymetry surveys provide an opportunity to analyse local geological structure where onshore areas afford limited exposure. Semi-automated lineament detection methods are necessary for areas of large coverage where a manual analysis would be subjective and timeconsuming. However, semi-automated approaches are dependent on effective feature extraction methods to identify genuine lineaments. This study offers solutions to common problems that can impede processing methods where sharp steps in the seafloor (e.g. palaeocoastlines) are present. Directional gradient, Sobel and Laplacian filters are explored as well as the hillshade and tilt derivative transform for feature extraction prior to applying an object-based image analysis lineament detection approach. The filtered datasets generally perform poorly with a marked improvement when using the hillshade transform. However, we find the azimuth-invariant tilt derivative, which incorporates a convolved vertical derivative, to be the most successful, identifying lineaments in a range of orientations and across a sharp step in the seafloor.
\end{abstract}

\footnotetext{
* Corresponding author 


\section{Introduction}

The bathymetry of the seafloor is complementary to the topography of the land and can describe various morphological features in the marine environment such as sedimentary bedforms or submerged outcrop (Hell et al., 2012). Bathymetric models produce a continuous surface of the seabed and provide an excellent means for viewing the structural complexity of exposed bedrock (Collier et al., 2006; Nixon et al., 2012). High-resolution data are particularly effective at defining areas of submerged outcrop and capture the detail of geological structure including bedding of strata and cross-cutting faults where these features dip $>10^{\circ}$ (Collier et al., 2006). Bathymetric data has also been shown to enhance the interpretation of seismic reflection data to better understand the geometry of structures and stratigraphy (Collier et al., 2006; Sanderson et al., 2017; Westhead et al., 2018).

Bathymetric data has been employed in a variety of studies to map geological structure and to enhance the interpretation of seismic reflection data (e.g. Collier et al., 2006; Nixon et al., 2012; Sanderson et al., 2017; Westhead et al., 2018). In some cases, bathymetric models can be derived from 3D seismic data, but generally multi-beam phase-difference methods are preferred (Power and Clarke, 2019). Remote mapping of seafloor lineaments complements land-based studies to help define the structural evolution of an area. Where submerged outcrop can be identified, high-resolution bathymetric data can provide an excellent input dataset for lineament detection. The data capture the detail of geological structure including bedding of strata and cross-cutting faults where these features dip $>10^{\circ}(\mathrm{Col}-$ lier et al., 2006). The extensive coverage available for these studies, often at high-resolution, can be cumbersome for manual methods. The ability to semi-automate lineament extraction and loop through a range of azimuths has meant that more objective lineament maps can be created compared to manual methods (e.g. Rahnama and Gloaguen, 2014; Middleton et al., 2015; Šilhavý et al., 2016; Yeomans et al., 2019). Therefore, a semi-automated lineament detection method can be desirable and increase the objectivity of the analysis. However, semi-automated methods require prior feature extraction to enhance data and target desirable structures. This is key for mapping offshore lineaments and poor feature extraction can be detrimental to the analysis.

This study investigates the effectiveness of different operators as a means for feature extraction, including direc- 
Application of the tilt derivative transform to bathymetric data

tional gradient and Sobel filters, azimuth-invariant Laplacian filters as well as transforms such as hillshading and the tilt derivative (TDR). It is worth noting that the use of directional filtering has become less popular over time due to the availability of more rigorous algorithms (Airo, 2013). However, many studies still implement the use of directional filters as a first pass for lineament mapping (Mallast et al., 2011; Sedrette and Rebaï, 2016). The study uses bathymetric data from SW England over a classic area of offshore NW Devon, illustrated in Figure 1 and utilises a state-of-the-art Object-based Image Analysis (OBIA) lineament detection method designed by Yeomans et al. (2019). A small subset of the study area over the platform edge is highlighted; full analyses are included in the Supplementary Information.

Understanding how different filters and transforms affect the final lineament population is important for selecting the most appropriate feature extraction tool when applying semi-automated methods. The different visualisations tested here test the importance of not only weighting azimuth equally but also examines how vertical changes in bathymetry can affect the results. Furthermore, we examine means of semi-automatically identifying areas of sediment cover that may lead to false positive lineaments and the potential effect of those spurious results if not removed. The study forms a precursor prior to lineament detection and structural analysis of offshore areas at a regional scale.

\subsection{Geological setting}

The geology of the study area comprises Culm Basin rocks which were deformed during Variscan orogenesis creating gently plunging chevron folds and predominantly NNW-directed thrusts (Rattey and Sanderson, 1984; Holder and Leveridge, 1986; Lloyd and Chinnery, 2002; Leveridge and Hartley, 2006). During this time, strike-slip transfer faults were formed in a NW to NNW orientation (Leveridge et al., 2002). Intraplate tectonics brought about subsequent phases of extension during the Permo-Triassic (Shail and Alexander, 1997). This was followed by the onset of Atlantic opening in the latest Jurassic-Cretaceous before Alpine collision caused minor inversion and substantial Cenozoic strike-slip movement (Holloway and Chadwick, 1986; Cheadle et al., 1987; Chapman, 1989; Hillis et al., 2008). These NW-SE structures, and subordinate NNE-SSW structures, have been reactivated multiple times during this period (Shail and Alexander, 1997; Ault et al., 2016), and have previously been investigated by Nixon et al. (2012) and Nyberg et al. (2018). They form the target for semi-automated lineament detection in this study and are of particular importance for understanding the post-Variscan structural evolution of the region. 


\section{Data and methods}

Manual lineament extraction studies can be effective at identifying structural features and creating maps of fault systems (e.g. Nixon et al., 2012). These studies often produce maps with long lineament traces that appear robust but can be subjective and dependent on the visualisation method (Scheiber et al., 2015). Biases can exist in various aspects of a manual analysis including lineament length and the scale/detail of fractures mapped, although user experience appears to be less important (Andrews et al., 2019). Semi-automated methods can mitigate these biases but the data often still require enhancement via feature extraction methods; thus requiring careful consideration. Directional filters such as gradient and Sobel kernels are effective at finding lineaments where the orientation is known; the same holds for the hillshade transform. Where this is not the case, the method must be azimuth-invariant and weight all orientations equally (e.g. Laplacian filters). Changes in the vertical plane of the source data can also influence the outputs, which is why the tilt derivative (TDR) transform is investigated in this study and compared to the aforementioned filters and hillshade transform.

\subsection{Bathymetric data}

The area of interest selected for this study is in the region offshore of Hartland Point, Devon (Figure 1b). Bathymetric data were downloaded at $2 \mathrm{~m}$ pixel resolution from the United Kingdom Hydrographic Office (UKHO) via the Admiralty Data Portal. These data have been collected as multibeam bathymetry through several surveys from 2007-2008; full details can be found in Supplementary Information. The site covers an area of submerged outcrop with a distinct platform area curtailed to the north of the study by an apparent palaeocoastline. This on-platform area extends some $2800 \mathrm{~m}$ west of the present coastline with a gentle gradient into deeper off-platform areas whereas to the north the on-platform area extends approximately $2300 \mathrm{~m}$ where a sharp drop $>10$ metres in the platform occurs over a palaeocoastline. Although sand cover becomes problematic in the westernmost part of the area, it is largely limited to the nearshore coves with small pockets found along the palaeocoast. The area was featured as part of a manual lineament analysis by Nixon et al. (2012) who determined a series of NW-SE and NNE-SSW trending fault sets that exhibit dextral and sinistral offsets, respectively. The area is also used as a case study site to showcase the NetworkGT plug-in for QGIS software, which consists of a suite of tools for geometric and topological analysis of two-dimensional 
fracture networks (Nyberg et al., 2018). Both Nixon et al. (2012) and Nyberg et al. (2018) have demonstrated that the area provides an excellent site for studying fault networks and this study will aim to extend this into deeper water.

\subsection{Filters and transforms}

Geospatial data, even after all processing steps have been completed, almost always require some further manipulation to enhance certain features prior to further analysis; for image or raster data, this often involves a filter or transform. There are a broad range of enhancements that can be tailored to the task and, when used with an appropriate semi-automated algorithm, a high degree of accuracy can be achieved (Sukumar et al., 2014). However, determining a suitable image enhancement can be difficult and potentially subjective especially depending on the target structure and the signal-to-noise ratio (Smith and Clark, 2005; Rahnama and Gloaguen, 2014).

Band pass filters, such as the gradient and Sobel operators, are effective at selecting a particular range (based on directionality). Low-pass and high-pass filters are useful for mitigating noise and enhancing the sharpness of features, respectively (Rahnama and Gloaguen, 2014). Transforms do not preferentially select data but convert the whole dataset to derive a new variable.

In this study, the directional gradient, Sobel and Laplacian filters as well as the hillshade and TDR transforms have been selected to demonstrate various feature extraction methods. These operators have been selected as they are commonly applied in lineament detection studies, be it manual or semi-automated, to enhance features prior to detection on a variety of datasets (Smithurst, 1990; Morris, 1991; Maini and Aggarwal, 2009; Airo and Wennerström, 2010; Mallast et al., 2011; Grebby et al., 2012; Hashim et al., 2013; Rahnama and Gloaguen, 2014; Sukumar et al., 2014; Middleton et al., 2015; Mwaniki et al., 2015; Scheiber et al., 2015; Sedrette and Rebaï, 2016; Šilhavý et al., 2016; Thiele et al., 2017; Yeomans et al., 2019; Xu et al., 2020). It is worth noting that other methods are available such as the Prewitt filter, Canny filter (Canny, 1986), Principal Component Analysis (e.g. Grebby et al., 2012), Hough transforms (e.g. Han et al., 2018) and geomorphological features (Kokinou and Panagiotakis, 2018) among others, which fall out of scope of this study. 


\subsubsection{Directional filters}

Directional filtering of spatial data is a well-established tool used to highlight features for lineament detection and structural mapping. The filter uses a weighted kernel to accentuate particular-oriented features, where features are perpendicular to the overall gradient of weights within the kernel. The use of directional filters was detailed by Moore and Waltz (1983) who provided a five-step framework for lineament enhancement that included smoothing, directional filtering, smoothing directional components, lineament extraction and scaling. For a 3 x 3 matrix, the process takes the focal pixel, $A_{0}$, and surrounding pixels $(B, C \ldots I)$ from the input data $\lambda$ in Equation 1 :

$$
\lambda_{3}=\left[\begin{array}{ccc}
B & C & D \\
E & A_{0} & F \\
G & H & I
\end{array}\right]
$$

Or, for a 5 x 5 matrix, Equation 2:

$$
\lambda_{5}=\left[\begin{array}{ccccc}
B & C & D & E & F \\
G & H & I & J & K \\
L & M & A_{0} & N & O \\
P & Q & R & S & T \\
U & V & W & X & Y
\end{array}\right]
$$

The values in $\lambda$ are convolved by a directional kernel in Equation 3 containing, in this case, a northwest gradient:

$$
G_{N W}=\left[\begin{array}{ccc}
-2 & -1 & 0 \\
-1 & 0 & 1 \\
0 & 1 & 2
\end{array}\right] * \lambda_{3}
$$

or a northeast gradient using Equation 4:

$$
G_{N E}=\left[\begin{array}{ccc}
0 & -1 & -2 \\
1 & 0 & -1 \\
2 & 1 & 0
\end{array}\right] * \lambda_{3}
$$

The results of these orthogonal filters can be combined as a magnitude using Equation 5:

$$
|G|=\sqrt{G_{N W}^{2}+G_{N E}^{2}}
$$

The weights used here have been chosen to emphasise the main directions of known faults in the study area. However, directional filtering can vary considerably depending on the task in hand, but generally take the form of a 3 x 3 kernel where the direction of positive-to-negative weighting provides the orientation of the kernel. 


\subsubsection{Sobel filter}

The Sobel filter is a commonly used edge detector technique and allows the calculation of the $X$ and $Y$ derivatives with a level of smoothing imparted via the kernel (Sobel and Feldman, 1973; Favalli and Fornaciai, 2017). It is another directional gradient-based method where the $X$ and $Y$ derivatives for the Sobel filter are calculated using Equation 6 and Equation 7, respectively.

$$
\begin{aligned}
G_{H} & =\left[\begin{array}{ccc}
1 & 0 & -1 \\
2 & 0 & -2 \\
1 & 0 & -1
\end{array}\right] * \lambda_{3} \\
G_{V} & =\left[\begin{array}{ccc}
1 & 2 & 1 \\
0 & 0 & 0 \\
-1 & -2 & -1
\end{array}\right] * \lambda_{3}
\end{aligned}
$$

These two first-order derivatives can then be combined into a gradient magnitude image using Equation 8:

$$
|G|=\sqrt{G_{H}^{2}+G_{V}^{2}}
$$

The Sobel filter is most sensitive to lineaments in the $\mathrm{X}$ and $\mathrm{Y}$ directions and diagonal components can be suppressed (Sobel and Feldman, 1973). The Sobel filter is essentially a modification of the Prewitt filter which does not account for smoothing. The introduction of a -2 weight to the filter (compared to a -1 for the Prewitt filter) adds a more 'circular' operation to the kernel that is advantageous over the Prewitt filter (Davies, 1986).

\subsubsection{Laplacian filter}

The Laplacian filter is a second-order derivative, non-directional filtering tool that has been widely applied for detecting structural lineaments from remotely sensed data (e.g. Grebby et al., 2012; Rahnama and Gloaguen, 2014; Al-Azemi and Divi, 2017). The Laplacian can be derived using Equation 9, which can be approximated by convolving the matrices described in Equation 10 and Equation 11 for a 3 x 3 kernel and 5 x 5 kernel, respectively.

$$
L_{(x, y)}=\nabla^{2} f_{(x, y)}=\frac{\delta^{2} f(x, y)}{\delta x^{2}}+\frac{\delta^{2} f(x, y)}{\delta y^{2}}
$$




$$
\begin{aligned}
L_{3} & =\left[\begin{array}{ccc}
0 & -1 & 0 \\
-1 & 4 & -1 \\
0 & -1 & 0
\end{array}\right] * \lambda_{3} \\
L_{5} & =\left[\begin{array}{ccccc}
0 & 0 & -1 & 0 & 0 \\
0 & -1 & -2 & -1 & 0 \\
-1 & -2 & 17 & -2 & -1 \\
0 & -1 & -2 & -1 & 0 \\
0 & 0 & -1 & 0 & 0
\end{array}\right] * \lambda_{5}
\end{aligned}
$$

The Laplacian filter is useful as it returns a smoother image where edges are located at the zero-contour (Marr and Hildreth, 1980). Being a second-order derivative, the Laplacian filter is more sensitive to noise in the data and may also be prone to edge-effects in the data (Maini and Aggarwal, 2009). Other derivations of the filter can mitigate this by combining Gaussian smoothing to enhance edge detection (e.g. Maini and Aggarwal, 2009; Rahnama and Gloaguen, 2014).

\subsubsection{Hillshade transform}

A shaded relief, or hillshade transformation, is a common tool for visualising topographic data and a useful first step for lineament mapping (Höfle and Rutzinger, 2011; Scheiber et al., 2015; Favalli and Fornaciai, 2017). It involves transforming a 2D image to highlight features in a particular direction based on a theoretical sun position; assuming a Lambertian surface and single light source at an infinite distance (Favalli and Fornaciai, 2017). The sun position is defined by an azimuth $\left(A_{s}\right)$ and zenith $\left(Z_{s}\right)$ and is combined with a slope $\left(S_{e}\right)$ and aspect $\left(A_{e}\right)$ derived from the elevation model to calculate the hillshade $(H)$ image (Equation 12) where all all angles are converted to radians.

$$
H=255 *\left(\left(\cos \left(Z_{s}\right) * \cos \left(S_{e}\right)\right)+\left(\sin \left(Z_{s}\right) * \sin \left(S_{e}\right) * \cos \left(A_{s}-A_{e}\right)\right)\right)
$$

Shadows are imparted on the image based on the azimuth and zenith of the light source where a zenith of zero would place the sun on the horizontal plane of reference. The single light source results in azimuth biasing and can change the apparent position of breaks in slope as well as the apparent convexity or concavity of a feature (Smith and Clark, 2005; Favalli and Fornaciai, 2017). This can be mitigated by using multiple hillshade images where at least two images are generated parallel, and orthogonal, to the principal lineament orientation to capture the main trends (Smith 
and Clark, 2005). This approach is similar to the methods of directional filters but is not as limited in orientation and the zenith imparts a level of sensitivity. However, lower zenith angles can lead to a loss of detail in shaded areas adjacent to prominent topography.

\subsubsection{Tilt derivative transform}

The tilt derivative (TDR) transform was first described by Miller and Singh (1994) whereby a tilt angle is determined by the arctangent of the vertical and total horizontal derivative of the data $(T)$ (Equation 13). The transform was developed for use with potential field data, primarily magnetic data, but has since been applied to other datasets such as LiDAR data (Middleton et al., 2015) and the Total Count of radiometric data (Yeomans et al., 2019) where the vertical derivative is calculated through convolution.

$$
T D R=\tan ^{-1}\left(\frac{\frac{\partial T}{\partial z}}{\sqrt{\left(\frac{\partial T}{\partial x}\right)^{2}+\left(\frac{\partial T}{\partial y}\right)^{2}}}\right)
$$

The TDR transform is a useful tool for preserving low amplitude signals which may be attenuated over the dynamic range in the presence of a larger amplitude signal (Miller and Singh, 1994; Verduzco et al., 2004; Fairhead et al., 2004). Values are restricted to $\pm \pi / 2$ by the arctangent function, regardless of the derivative magnitudes, preserving low amplitude signals and reducing the effect of noise. Additionally, this feature assists the interpretation where the continuity of a body may vary due to lateral changes in signal (Verduzco et al., 2004). Furthermore, the zero-contour passes over or near the edge of bodies (Miller and Singh, 1994). These features make the TDR transform an effective tool for mapping edges or mapping minima/maxima.

\subsection{Lineament detection}

Lineament detection techniques have commonly taken a pixel-based approach to feature identification. The results have shown broad improvement over several decades but are still fallible in noisy data and in areas where lineaments appear discontinuous. Object-Based Image Analysis (OBIA) workflows allow the generation of spatially correlated groups of pixels or "image objects" to identify lineaments. The advantage of an OBIA approach is that objects have 
internal and relative statistics as well as a geospatial topology that can hone the classification (Lang, 2008). The use of these attributes can result in a more subjective assessment (Blaschke et al., 2004) but the analysis is more robust to noise compared to pixel-based methods (Van Den Eeckhaut et al., 2005, 2012). Image objects have proven an effective means for lineament detection and used on a variety of data types including spaceborne InSAR and Landsat data (Mavrantza and Argialas, 2006; Marpu et al., 2008), as well as airborne LiDAR, magnetic and radiometric data (Rutzinger et al., 2006; Middleton et al., 2015; Yeomans et al., 2019).

Herein, an OBIA workflow is used to capture lineaments in the bathymetry. Prior to the analysis, outliers were removed and the ranges for each filter and the hillside transform were linearly transformed to optimise performance within the algorithm; see Supplementary Information. The data are taken as a single input layer using the bottomup OBIA method described by Yeomans et al. (2019). The method efficiently performs lineament extraction from large raster datasets whilst creating slightly shorter lineament segments compared to top-down OBIA methods (e.g. Middleton et al., 2015; Yeomans et al., 2019). For this study, line extraction was completed in two phases and optimised for each data input. The first phase searched for NW-SE lineaments in the range $120^{\circ}$ to $175^{\circ}$ using a line width of 2 pixels, the second phase targeted NNE-SSW lineaments in the range $005^{\circ}$ to $060^{\circ}$ with a line width of 1 pixel. The resultant image objects were then merged and processed as per the approach outlined in Yeomans et al. (2019). Note that lineaments between $060^{\circ}$ and $120^{\circ}$ were purposefully not included in the detection ranges for the two phases as these equate to bedding surfaces that varied due to tight fold axes.

\section{Results and discussion}

In this section, we present visualisations using each of the filters and transforms introduced above and the subsequent derived lineaments. The semi-automated OBIA approach to lineament detection ensures an objective interpretation between different visualisations of the data. The resultant lineament populations are examined qualitatively and quantitatively to determine the merits of each operator whilst a semi-automated approach to data quality assessment allows the removal of likely false positive lineaments. 


\subsection{Feature extraction methods}

The operations performed on the data are presented in Figure 2, over the magnified area (illustrated in Figure 1b). This small subset of the study shows the edge of the platform and provides a good comparison of how the filters and transforms perform across this pronounced change in depth. It can be seen from Figure $2 \mathrm{a}$ that the magnitude of the gradient filter is effective at dealing with the sharp break in the data but, because it is an edge detector, tends toward highlighting the edges of submerged outcrop blocks, rather than identifying fractures in the bedrock. The magnitude of the Sobel filter is similar in its output due to the subtle difference in its kernel with the magnitude of gradient (Equations 5 and 8), the result in Figure $2 \mathrm{~b}$ captures edges of blocks and is not well suited to define minima. Although the filtered data range appears to be better at recognising structure in the off-platform data, it is oversaturated on the platform resulting in an apparent loss of resolution.

Compared to the previous filters, the Laplacian filter produces a smoother visualisation of the data. The $3 \times 3$ kernel shown in Figure 2c provides a slight enhancement on the data to highlight structures but is overall indistinct at this scale and appears to have greater noise. The 5 x 5 kernel (Figure 2d) emphasises more structures in both on-platform and off-platform areas whilst reducing noise to give a sharper image.

Figure 2e displays the hillshade transform for the illumination azimuth of $225^{\circ}$ and zenith of $45^{\circ}$ that enhances the NW-SE structures in the area. It should be noted that the method also incorporates an orthogonal hillshade at $315^{\circ}$ and a $45^{\circ}$ zenith to enhance the subordinate NNE-SSW features. The image clearly detects structures in the on-platform areas of the seafloor but struggles to highlight such detail in the deeper off-platform areas. The tilt derivative provides a more complete picture where structures are equally apparent despite the step-change in platform height over the area. The use of a total horizontal derivative in the denominator means that there is no azimuthal bias to highlight particular orientations of lineaments in the data, as is the case with the hillshade transform.

\subsection{Lineament populations}

The derived lineaments are presented and discussed with respect to the relative performance of each operator. A visual inspection is presented of a subset of the area (outlined in Figure 1b) is used to provide a visual assessment 
Application of the tilt derivative transform to bathymetric data 
Application of the tilt derivative transform to bathymetric data

The number of lineaments derived from gradient-filtered data across Zone 1 is not substantial, with the majority of lineaments found over on-platform areas. Figure 3a weakly defines some NW-SE features in the data but the lack of contiguous segments make interpretation more difficult. The off-platform areas perform even more poorly and this is likely a function of the lack of smoothing (as mentioned for Zone 2) but also the more subtle features in offplatform areas being masked by the significant gradient caused across the step in the seafloor. In Figure $3 \mathrm{~b}$, lineaments derived from Sobel-filtered data show a reasonable level of detail in the on-platform areas although continuous features are difficult to observe. The off-platform areas are an improvement with respect to the gradient methods but also lack easily identifiable structures. Despite the smoothing component incorporated into the Sobel kernels, these off-platform lineaments remain elusive.

Lineaments derived from Laplacian-filtered data show reasonable on-platform features. The 3 x 3 kernel (Figure $3 \mathrm{c}$ ) identifies an abundance of short lineaments, although these produce short segments that do not easily define NW-SE or NNE-SSW trending structures. The off-platform lineaments appear to be largely a function of noise, not giving clear definition to any features, and are considered false positives. In contrast, the $5 \times 5$ kernel (Figure $3 \mathrm{~d}$ ) produces a less noisy lineament population and longer lineament segments, clearly defining some key structures in Zone 1 . The off-platform areas, however, do not display any distinguishable features. The interpretation that the $5 \times 5$ kernel has been effective at suppressing noisy lineaments further suggests off-platform lineaments detected using data filtered by the $3 \times 3$ kernel are spurious.

A vast population of lineaments across the on-platform area has been generated from the hillshade-transformed data (Figure 3e). Major NW-SE structures are clearly identified and are traceable with long segment lengths to the lineaments. The population also contains a significant amount of small lineaments which appear to be more robust when compared with the noisier populations seen in Figure $3 \mathrm{c}$ from the 3 x 3 Laplacian filter. However, the off-platform area underperforms, showing few lineaments and many of those that are detected do not have contiguous segments. In contrast, lineaments derived from the TDR-transformed data show clear structures, albeit with fewer short segments in some areas (Figure 3f). The lineaments detected define clear NW-SE trending features in on-platform areas and also identify some subordinate NNE-SSW structures. Importantly, the off-platform areas show an abundance of lineaments, 
which present contiguous segments, and are traceable back to on-platform features; although, many are generated in areas of sediment cover which could be the result of amplified noise.

\subsubsection{Lineament analysis}

A statistical analysis of the lineaments for each feature extraction method over the whole study area are presented in Table 1. These describe the mean, standard deviation and median of each lineament population as well as the range, skewness and kurtosis for lineament lengths and their approximate depth. The number of observations for each extraction method is also listed where a clear distinction can be made between the number of lineaments derived from transformed data versus filtered data where the hillshade transform identifies the highest number of lineaments.

Lengths for each extraction method all show a strong positive skew and high kurtosis, characteristic of populations where more short lineaments are identified over larger ones. This indicates that the mean is not as reliable a metric and the median should be used. Shorter median lineament lengths are detected by the gradient and Sobel directional filters and this is reflected in their range. The Laplacian filters provide good lineament lengths, comparable to the hillshade and TDR transform but the $3 \times 3$ kernel produces a large amount of lineaments but never $>100 \mathrm{~m}$. Equally, the $5 \times 5$ kernel produces the third lowest number of lineaments whilst having a high standard deviation indicating a small but varied population. The hillshade and TDR transform operators perform well produce large lineament populations, at good median lengths with the largest ranges.

The depth values are calculated by assigning the point value from the bathymetric data at the centroid of the polyline in the vector data where the centroid is assumed to approximate the midpoint of the lineament. The depth data generally show a more Gaussian distribution represented by skewness values close to zero, albeit more flattened as seen by the low kurtosis. Therefore, in contrast to lineament lengths, the mean is a more reliable metric for identifying the average depths at which lineaments are sensed. The hillshade transform and the Laplacian, Sobel and gradient-based filters show a fairly consistent picture of the depths at which lineaments are identified but there is a marked difference in the depth at which lineaments are detected for the TDR transform, which clearly shows a greater mean depth and higher standard deviation. This is further illustrated by the kernel density estimation in Figure 4 where the TDR shows a distinctly different shape at depths deeper than $-28 \mathrm{~m}$ (i.e. off-platform areas). It can be seen that between depths of 
$-28 \mathrm{~m}$ and $0 \mathrm{~m}$ the trend in lineament density is similar for all methods, however, the large population of lineaments noted for the $5 \mathrm{x} 5$ Laplacian kernel in Table 1 is focused between depths of $-16 \mathrm{~m}$ to $-20 \mathrm{~m}$. The KDE function shows relative density of lineaments, thus, the lower values within this range for the TDR transform do not represent fewer lineaments at these depths but demonstrate that the method captures lineaments across the depth range.

Axial data for lineaments derived for each method have been calculated and presented in rose diagrams in Figure 5. These have been prepared using equal-area wedge rose plots following the guidelines presented by Sanderson and Peacock (2020). Bin sizes are suggested to be calculated by dividing the range ( $180^{\circ}$ for axial data) by the number of observations to the nearest $5^{\circ}$. Due to the large population sizes this resulted in values $\ll 1^{\circ}$; in this case a bin size of $5^{\circ}$ intervals was selected.

The rose diagram for the directional gradient-based feature extraction method (Figure 5a) is clearly aligned to the two axes upon which the directions were selected and clearly highlights the orientation of major NW-SE and subordinate minor NNE-SSW structures. The Sobel filter (Figure 5b), where the directional components were aligned N-S and E-W captures both orientations of features, but displays greater variation about these directions, particularly in the NW-SE axis. The Laplacian filters present quite a different population of lineament orientations being detected. The $3 \times 3$ kernel (Figure 5c) captures a strong NNW-SSW component of equal magnitude to the major NW-SE structures whereas the 5 x 5 kernel in Figure 5d presents a more consistent picture of major NW-SE and subordinate NNE-SSW features. The likely explanation for the discrepancies between the two kernels is, whilst both are second order derivatives and more sensitive to noise, the $5 \times 5$ kernel allows more smoothing compared to the $3 \times 3$ kernel which struggles to mitigate noisy data. The rose diagram of the hillshade transform (Figure 5e) highlights the major NW-SE trend strongly with little variation other than a subordinate NNE-SSW trend which is strongly aligned perpendicular to the orthogonal hillshade azimuth. The TDR transform produces a range of lineaments, with a strong NW-SE population, however, the subordinate NNE-SSW trend is either underrepresented or skewed more towards the NNE-SSW orientation observed in the $3 \times 3$ Laplacian filter. Interestingly, this NNE trend is present in all lineament populations apart from the hillshade method where it is clearly absent. 
Application of the tilt derivative transform to bathymetric data

\subsection{The effect of false positive results}

The data quality assessment using the TRI identified areas sediment cover assuming these remain smooth and free of artefacts. By using these areas as a mask, likely spurious lineaments can be spatially filtered and removed as false positive results. Due to the low numbers of selected lineaments for all methods apart from the TDR transform, only the TDR-derived lineaments are used here to analyse the effects of false positives on the population. The total number of false positives removed from spatial filtering from the TDR-derived dataset was 549 (Table 1). These are presented and compared to the remaining lineament population in Figure 6 where equal-area wedge rose diagrams are implemented.

A rose diagram of the unfiltered data is shown in Figure 6a where a strong modal axis can be identified in both a NWSE and NNE-SSW orientation. Figure $6 \mathrm{~b}$ shows a strong modal axis approximately NNE-SSW and are concentrated over areas that were interpreted as sediment-covered due to their smoothness when applying the TRI mask. The TDR transform is often heralded for its ability to give equal weight to minor features on a surface whilst in the presence of larger structures ((Miller and Singh, 1994; Verduzco et al., 2004), however, the strong population in this orientation is likely caused by small artefacts that are exaggerated by the TDR transform. We therefore suggest caution when using the TDR transform in areas of sediment cover. Furthermore, the rose plot of data generated by the $3 \times 3$ kernel of the Laplacian filter in Figure 5c shows a similarly strong NNE-SSW trend which may imply that similar artefacts are being identified by this filter but are not found of areas of sediment cover.

By conducting an assessment of these potentially spurious lineaments, it an oversampling of NNE-oriented lineaments can be demonstrated. Removing these from the population results in a more representative set of lineaments where a subordinate NNE-SSW trend is comparable with the original study of Nixon et al. (2012). Whether these false positive results are due to small sand waves upon the sediment cover, or whether they represent artefacts caused by the interaction with unconsolidated substrate is unclear. The identification of areas that do not represent submerged outcrop determines that the source is not geological. The strong modal axis identified in the $3 \times 3$ Laplacian filter, and the susceptibility of the filter to noise, may indicate a sonic source but further investigation is beyond the scope of this study. 


\subsection{Comparison of methods}

The different feature extraction techniques tested in this study show markedly different lineament populations that are variably affected by the sharp break in the seafloor. Gradient-based filters are the least effective, despite the initial kernels being selected to emphasise NW and NE gradients and the rose diagrams show that the directional filtering has forced the lineament population towards these major trends. The Sobel filter underperforms, relative to other methods, even with smoothing incorporated into the kernel but does allow greater flexibility away from the major modal axes. Neither of these gradient-based filters are capable of capturing lineaments in the off-platform areas.

The Laplacian filters successfully identify structures, albeit discontinuously, with a distinct improvement when using the 5 x 5 kernel. Despite reasonable success on the platform, the filters fail to capture any significant structure in the off-platform area. The azimuth-invariant nature of these kernels is demonstrated in the rose diagrams where major NW-SE faults are still readily identified as a modal axis, but with greater contributions from the subordinate NNE-SSW trend. These Laplacian filters are second-order derivatives and sensitive to noise, which may be manifest in the 3 x 3 kernel where a NNE-SSW modal axis dominates (Figure 5c). In comparison, the $5 \times 5$ kernel does not capture this, which may be a function of greater smoothing over the larger kernel.

Numerous, clear NW-SE lineaments are identified when using the hillshade transform in on-platform areas. The transform is the most prolific with nearly 8000 lineaments being identified despite being processed to only focus on NW-SE trends, as evidenced by the rose diagram in Figure $5 \mathrm{~b}$. Including another hillshade with an orthogonal azimuth (e.g. Scheiber et al., 2015) or taking a multi-hillshade clustering approach (e.g. Šilhavý et al., 2016) would likely further improve this analysis. Unfortunately, off-platform areas do not capture features to the same level of consistency and are not easily interpretable.

The TDR transform captures the two major NW-SE and NNE-SSW trends in the area and produced the second largest lineament population, with good lineament lengths. It also was the most effective operator for detecting lineaments in both on- and off-platform areas across the break in the seafloor. This is due to the inclusion of the vertical derivative that provides a normalisation to vertical changes across the study area. However, the transform is potentially 
fallible if not applied with care to identify false positive lineaments. Due to the sensitivity of the algorithm, and the equal weighting of large and small lineaments, spurious lineaments are produced over areas interpreted as sediment cover and are thus do not represent a geological lineament. Spatial filtering, using a TRI layer, can efficiently remove these false positive lineaments from the population and return a more realistic subset of detected lineaments.

Segmented lineaments are common across all analyses and may be a reflection of slight changes in fault properties along strike (e.g. damage zones) that may have preferentially eroded in the seafloor. Thus, post-processing to link these segments should be investigated (e.g. topological methods such as Panagiotakis and Kokinou, 2015). Furthermore, the possible detection of amplified noise in some off-platform areas by the TDR transform could be mitigated by prior application of a smoothing filter. Despite this, the TDR transform is still considered to be the best operators for lineament detection where a sharp break in slope is present in the source data.

\section{Conclusions}

Six different operators have been tested as feature extraction tools prior to semi-automated lineament detection. The different filters and transforms have been assessed based on their performance to detect lineaments from bathymetric data where step-changes (palaeocoastlines) in the seafloor platform are present. These included the magnitude of gradient through combined NW and NE gradient filters, the magnitude of the Sobel filter, two Laplacian filters $(3 \times 3$ and a 5 x 5 kernels) as well as the hillshade and TDR transform.

The bathymetric data used in this study show a network of NW-SE and NNE-SSW faults sets that can be identified using semi-automated lineament detection techniques. Semi-automated approaches have been demonstrated to produce markedly different lineament populations based on different feature extraction tools. Thus, testing over a small area is an important step prior to using semi-automated methods on regional scale.

The semi-automated OBIA lineament detection method of Yeomans et al. (2019) has been applied to bathymetric data to analyse the six operators, of which, the TDR transform was most successful. The algorithm also performed well 
when applied to the hillshade transform, demonstrating the potential to greatly extend the use of the algorithm to analyse other geospatial datasets. The study is noteworthy for developers of future semi-automated lineament algorithms and careful consideration of the feature extraction methods implemented and their potential to generate false positives through noise.

The TDR transform is considered to be the most effective operator for identifying lineaments. This study has demonstrated that the use of the TDR transform enhances the data so that abrupt changes in the bathymetry, such as palaeocoastlines, are not detrimental to the analysis. In turn, this increases the area available for interpretation of offshore fault zones. Whilst the resulting lineament population contains longer lineament segments than the other operators, it is worth noting that the TDR transform is not a panacea for lineament detection techniques. For example, subtle artefacts in the data over sediment-covered areas have been amplified and mapped as lineaments. These required careful post-processing using a semi-automated spatial filter based on the texturally-derived TRI. Nevertheless, the TDR transform provides an excellent tool for generating meaningful lineament populations across large studies areas that may contain significant changes in elevation.

\section{Acknowledgements}

We thank Camilla Palmiotto and an anomymous reviewer for constructive comments that enhanced this manuscript. CMY is funded by a NERC Highlights grant (NE/S003886/1) on the GWatt project. MH is supported by a NERC GW4+ Doctoral Training Partnership studentship (NE/L002434/1). JJL holds a Vice-Chancellor Scholarship at the University of Exeter. The data used in this study have been sourced from the UK Hydrographic Office and accessed via the Admiralty Marine Data Portal. The British Geological Survey is thanked for making the BGS Geology 625k (DiGMapGB-625) data freely available. Dr Matt Hall is kindly thanked for his insights into some of the nuances of QGIS and color ramps. The Software Underground community is also thanked for their assistance deciphering Python errors. 


\section{References}

Airo, M.L., 2013. Structural interpretation of airborne geophysical data: examples from Finland. Technical Report. Geologian Tutkimuskeskus (GTK). Espoo.

Airo, M.L., Wennerström, M., 2010. Application of regional aeromagnetic data in targeting detailed fracture zones. Journal of Applied Geophysics 71,62-70. URL: http://linkinghub.elsevier.com/retrieve/pii/S0926985110000388, doi:10.1016/j.jappgeo.2010.03.003. Al-Azemi, A.M., Divi, R., 2017. Extraction of Geological Structural Lineaments in Northern Kuwait Using High Resolution Landsat 8 ETM+ Satellite Images and Edge Enhancement Techniques. Journal of Engineering Sciences and Information Technology 1, 18-35.

Andrews, B.J., Roberts, J.J., Shipton, Z.K., Bigi, S., Tartarello, M.C., Johnson, G., 2019. How do we see fractures? Quantifying subjective bias in fracture data collection. Solid Earth 10, 487-516. URL: https://www.solid-earth.net/10/487/2019/, doi:10.5194/ se-10-487-2019

Ault, A.K., Frenzel, M., Reiners, P.W., Woodcock, N.H., Thomson, S.N., 2016. Record of paleofluid circulation in faults revealed by hematite(UTh)/He and apatite fission-track dating: An example from Gower Peninsula fault fissures, Wales. Lithosphere 8, 379-385. doi:10 . 1130/L522 . 1.

Blaschke, T., Burnett, C., Pekkarinen, A., 2004. Image Segmentation Methods for Object-based Analysis and Classification, in: de Jong, S.M., van der Meer, F.D. (Eds.), Remote Sensing Image Analysis: Including the Spatial Domain. Springer Netherlands, pp. $211-236$.

Canny, J., 1986. A computational approach to edge detection. IEEE Transactions on Pattern Analysis and Machine Intelligence 8.

Chapman, T.J., 1989. The Permian to Cretaceous structural evolution of the Western Approaches Basin (Melville sub-basin), UK. Geological Society Special Publication 44, 177-200. doi:10.1144/GSL.SP.1989.044.01.11.

Cheadle, M.J., McGeary, S., Warner, M.R., Matthews, D.H., 1987. Extensional structures on the western UK continental shelf: A review of evidence from deep seismic profiling. Geological Society Special Publication 28, 445-465. doi:10.1144/GSL.SP.1987.028.01.28.

Collier, J.S., Gupta, S., Potter, G., Palmer-Felgate, A., 2006. Using bathymetry to identify basin inversion structures on the English Channel shelf. Geology 34, 1001. URL: https://pubs.geoscienceworld.org/geology/article/34/12/1001-1004/129412, doi:10.1130/ G22714A.1.

Davies, E.R., 1986. Constraints on the design of template masks for edge detection. Pattern Recognition Letters 4, 111-120. doi:10.1016/ $0167-8655$ (86) $90032-2$.

Fairhead, J.D., Mackenzie, C., Green, C.M., Verduzco, B., 2004. A new set of magnetic field derivatives for mapping mineral prospects. ASEG Extended Abstracts 2004, 1-4. URL: https://www.tandfonline.com/doi/full/10.1071/ASEG2004ab042, doi:10.1071/ ASEG2004ab042.

Favalli, M., Fornaciai, A., 2017. Visualization and comparison of DEM-derived parameters. Application to volcanic areas. Geomorphology 290, 69-84. URL: http://dx.doi.org/10.1016/j.geomorph.2017.02.029, doi:10.1016/j.geomorph.2017.02.029.

Grebby, S., Cunningham, D., Naden, J., Tansey, K., 2012. Application of airborne LiDAR data and airborne multispectral imagery to structural mapping of the upper section of the Troodos ophiolite, Cyprus. International Journal of Earth Sciences 101, 1645-1660. doi:10.1007/ s00531-011-0742-3.

Han, L., Liu, Z., Ning, Y., Zhao, Z., 2018. Extraction and analysis of geological lineaments combining a DEM and remote sensing images from the northern Baoji loess area. Advances in Space Research 62, 2480-2493. URL: https://doi.org/10.1016/j.asr.2018.07.030, doi:10. $1016 /$ j.asr.2018.07.030.

Hashim, M., Ahmad, S., Johari, M.A.M., Pour, A.B., 2013. Automatic lineament extraction in a heavily vegetated region using Landsat Enhanced Thematic Mapper (ETM+) imagery. Advances in Space Research 51, 874-890. URL: http://dx .doi .org/10.1016/j . asr .2012.10.004, doi:10.1016/j.asr.2012.10.004.

Hell, B., Broman, B., Jakobsson, L., Jakobsson, M., Magnusson, A., Wiberg, P., 2012. The use of bathymetric data in society and science: A review from the Baltic Sea. Ambio 41, 138-150. doi:10.1007/s13280-011-0192-y.

Hillis, R.R., Holford, S.P., Green, P.F., Doré, A.G., Gatliff, R.W., Stoker, M.S., Thomson, K., Turner, J.P., Underhill, J.R., Williams, G.A., 2008. Cenozoic exhumation of the southern British Isles. Geology 36, 371-374. URL: https://pubs.geoscienceworld. org/geology/ article/36/5/371-374/29723, doi:10.1130/G24699A.1.

Höfle, B., Rutzinger, M., 2011. Topographic airborne LiDAR in geomorphology: A technological perspective. Zeitschrift fur Geomorphologie 55, 1-29. doi:10.1127/0372-8854/2011/0055S2-0043.

Holder, M.T., Leveridge, B.E., 1986. A model for the tectonic evolution of south Cornwall. Journal of the Geological Society, London 143, 125-134. doi:10.1144/gsjgs.143.1.0125.

Holloway, S., Chadwick, R.A., 1986. The Sticklepath-Lustleigh fault zone: Tertiary sinistral reactivation of a Variscan dextral strike-slip fault. Journal of the Geological Society, London 143, 447-452.

Kokinou, E., Panagiotakis, C., 2018. Structural pattern recognition applied on bathymetric data from the Eratosthenes Seamount (Eastern Mediterranean, Levantine Basin). Geo-Marine Letters 38, 527-540. doi:10.1007/s00367-018-0553-7.

Lang, S., 2008. Object-based image analysis for remote sensing application: modeling reality - dealing with complexity, in: Blaschke, T., Lang, S., Hay, G.J. (Eds.), Object-Based Image Analysis: Spatial Concepts for Knowledge-Driven Remote Sensing Applications. Springer-Verlag, Berlin, pp. 3-27.

Leveridge, B.E., Hartley, A.J., 2006. The Varisan Orogeny: the development and deformation of Devonian/Carboniferous basins in SW England and South Wales, in: Brenchley, P.J., Rawson, P.F. (Eds.), The Geology of England and Wales. 2nd ed.. The Geological Society, London. chapter 10, pp. 225-256.

Leveridge, B.E., Holder, M.T., Goode, A.J.J., Scrivener, R.C., Jones, N.S., Merriman, R.J., 2002. Geology of the Plymouth and south-east Cornwall area. Memoir of the British Geological Survey, Sheet 348. England and Wales.

Lloyd, G.E., Chinnery, N., 2002. The Bude Formation, SW England - three-dimensional, intra-formational Variscan imbricate stack? Journal of Structural Geology 24, 1259-1280.

Maini, R., Aggarwal, H., 2009. Study and comparison of various image edge detection techniques. International Journal of Image Processing 3, 1-11. doi:http : / /www . doaj .org/doaj?func=openurl\&genre=article\&issn=19852304\&date=2009\&volume=3\&issue=1\&spage=1. 
Mallast, U., Gloaguen, R., Geyer, S., Rödiger, T., Siebert, C., 2011. Derivation of groundwater flow-paths based on semi-automatic extraction of lineaments from remote sensing data. Hydrology and Earth System Sciences 15, 2665-2678. doi:10.5194/hess-15-2665-2011.

Marpu, P.R., Niemeyer, I., Nussbaum, S., Gloaguen, R., 2008. A procedure for automatic object-based classification, in: Blaschke, T., Lang, S. Hay, G.J. (Eds.), Object-Based Image Analysis: Spatial Concepts for Knowledge-Driven Remote Sensing Applications, pp. 169-184. doi:10. 1007/978-3-540-77058-9.

Marr, D., Hildreth, E., 1980. Theory of edge detection. Proceedings of the Royal Society of London. Series B. Biological Sciences 207, 187-217. URL: https://royalsocietypublishing.org/doi/10.1098/rspb.1980.0020, doi:10.1098/rspb.1980.0020.

Mavrantza, O.D., Argialas, D.P., 2006. Object-oriented image analysis for the identification of geologic lineaments. International Archives of Photogrammetry, Remote Sensing and Spatial Information Sciences 36, 1-6.

Middleton, M., Schnur, T., Sorjonen-ward, P., Hyvönen, E., 2015. Geological lineament interpretation using the Object-Based Image Analysis Approach: results of semi-automated analyses versus visual interpretation. Geological Survey of Finland, Special Paper 57, $135-154$.

Miller, H.G., Singh, V., 1994. Potential field tilt - a new concept for location of potential field sources. Journal of Applied Geophysics 32, $213-217$. doi:10.1016/0926-9851(94)90022-1.

Moore, G.K., Waltz, F.A., 1983. Objective procedures for lineament enhancement and extraction (Eros Data Center). Photogrammetric Engineering \& Remote Sensing 49, 641-647.

Morris, K., 1991. Using knowledge-base rules to map the three-dimensional nature of geological features. Photogrammetric Engineering \& Remote Sensing 57, 1209-1216.

Mwaniki, M.W., Moeller, M.S., Schellmann, G., 2015. A comparison of Landsat 8 (OLI) and Landsat 7 (ETM+) in mapping geology and visualising lineaments: A case study of central region Kenya. International Archives of the Photogrammetry, Remote Sensing and Spatial Information Sciences - ISPRS Archives 40, 897-903. doi:10.5194/isprsarchives-XL-7-W3-897-2015.

Nixon, C.W., Sanderson, D.J., Bull, J.M., 2012. Analysis of a strike-slip fault network using high resolution multibeam bathymetry, offshore NW Devon U.K. Tectonophysics 541-543, 69-80. URL: http://dx . doi .org/10.1016/j . tecto.2012.03.021, doi:10.1016/j .tecto. 2012.03 .021$.

Nyberg, B., Nixon, C.W., Sanderson, D.J., 2018. NetworkGT: A GIS tool for geometric and topological analysis of two-dimensional fracture networks. Geosphere 14, 1618-1634. doi:10.1130/GES01595.1.

Panagiotakis, C., Kokinou, E., 2015. Linear pattern detection of geological faults via a topology and shape optimization method. IEEE Journal of Selected Topics in Applied Earth Observations and Remote Sensing 8, 3-11. doi:10.1109/JSTARS.2014. 2363080.

Power, H.E., Clarke, S.L., 2019. 3D seismic-derived bathymetry: a quantitative comparison with multibeam data. Geo-Marine Letters 39, 447-467. doi:10.1007/s00367-019-00596-w.

Rahnama, M., Gloaguen, R., 2014. TecLines: A MATLAB-Based Toolbox for Tectonic Lineament Analysis from Satellite Images and DEMs, Part 1: Line Segment Detection and Extraction. Remote Sensing 6, 5938-5958. URL: http://www.mdpi.com/2072-4292/6/7/5938, doi:10.3390/rs6075938.

Rattey, P.R., Sanderson, D.J., 1984. The structure of SW Cornwall and its bearing on the emplacement of the Lizard Complex. Journal of the Geological Society, London 141, 87-95.

Rutzinger, M., Höfle, B., Pfeifer, N., Geist, T., Stötter, H., 2006. Object based analysis of airborne laser scanning data for natural hazard purposes using open source components, in: 1st International Conference on Object-based Image Analysis, p. 5.

Sanderson, D.J., Dix, J.K., Westhead, K.R., Collier, J.S., 2017. Bathymetric mapping of the coastal and offshore geology and structure of the Jurassic Coast, Weymouth Bay, UK. Journal of the Geological Society 174, 498-508. URL: http://jgs . 1yellcollection. org/lookup/ doi/10.1144/jgs2016-070, doi:10.1144/jgs2016-070.

Sanderson, D.J., Peacock, D.C., 2020. Making rose diagrams fit-for-purpose. Earth-Science Reviews 201, 103055. URL: https:// doi.org/10.1016/j.earscirev.2019.103055https://linkinghub.elsevier.com/retrieve/pii/S001282521930594X, doi:10. 1016/j.earscirev.2019.103055.

Scheiber, T., Fredin, O., Viola, G., Jarna, A., Gasser, D., Łapińska-Viola, R., 2015. Manual extraction of bedrock lineaments from high-resolution LiDAR data: methodological bias and human perception. Journal of the Geological Society of Sweden (GFF) 137, 362-372. doi:10.1080/ 11035897.2015 .1085434 .

Sedrette, S., Rebaï, N., 2016. Automatic extraction of lineaments from Landsat Etm+ images and their structural interpretation: Case Study in Nefza region (North West of Tunisia). Journal of Research in Enviromental and Earth Sciences 04, 139-145.

Shail, R.K., Alexander, A.C., 1997. Late Carboniferous to Triassic reactivation of Variscan basement in the western English Channel: evidence from onshore exposures in south Cornwall. Journal of the Geological Society, London 154, 163-168. doi:10.1144/gs jgs.154.1.0163.

Šilhavý, J., Minár, J., Mentlík, P., Sládek, J., 2016. A new artefacts resistant method for automatic lineament extraction using Multi-Hillshade Hierarchic Clustering (MHHC). Computers \& Geosciences 92, 9-20.

Smith, M.J., Clark, C.D., 2005. Methods for the visualization of digital elevation models for landform mapping. Earth Surface Processes and Landforms 30, 885-900. doi:10.1002/esp. 1210.

Smithurst, L.J.M., 1990. Structural remote sensing of south-west England. Proceedings of the Ussher Society 7, $236-241$.

Sobel, I., Feldman, G., 1973. A 3x3 Isotropic Gradient Operator for Image Processing. Pattern Classification and Scene Anlaysis , $271-272$.

Sukumar, M., Venkatesan, N., Babu, C.N.K., 2014. A review of various lineament detection techniques for high resolution satellite images. International Journal of Advanced Research in Computer Science and Software Engineering 4, 72-78.

Thiele, S.T., Grose, L., Samsu, A., Micklethwaite, S., Vollgger, S.A., Cruden, A.R., 2017. Rapid, semi-automatic fracture and contact mapping for point clouds, images and geophysical data. Solid Earth 8, 1241-1253. URL: https://www.solid-earth.net/8/1241/2017/, doi:10. 5194/se-8-1241-2017.

Tobler, W., 1988. Resolution, Resampling and All That, in: Mounsey, H., Tomlinson, R. (Eds.), Building Data Bases for Global Science. Taylor \& Francis, London, pp. 129-137.

Van Den Eeckhaut, M., Kerle, N., Poesen, J., Hervás, J., 2012. Object-oriented identification of forested landslides with derivatives of single 
pulse LiDAR data. Geomorphology 173-174, 30-42. URL: http://dx.doi.org/10.1016/j.geomorph.2012.05.024, doi:10.1016/j . geomorph.2012.05.024.

Van Den Eeckhaut, M., Poesen, J., Verstraeten, G., Vanacker, V., Moeyersons, J., Nyssen, J., van Beek, L.P., 2005. The effectiveness of hillshade maps and expert knowledge in mapping old deep-seated landslides. Geomorphology 67,351-363. doi:10.1016/j.geomorph.2004.11.001.

Verduzco, B., Fairhead, D., Green, C.M., MacKenzie, C., 2004. New insights into magnetic derivatives for structural mapping. The Meter Reader , 116-119.

Westhead, R.K., McCarthy, D.J., Collier, J.S., Sanderson, D.J., 2018. Spatial variability of the Purbeck-Wight Fault Zone-a long-lived tectonic element in the southern UK. Proceedings of the Geologists' Association 129, 436-451. URL: http://dx.doi.org/10.1016/j.pgeola. 2017.08.005, doi:10.1016/j.pgeola.2017.08.005.

Xu, J., Wen, X., Zhang, H., Luo, D., Li, J., Xu, L., Yu, M., 2020. Automatic extraction of lineaments based on wavelet edge detection and aided tracking by hillshade. Advances in Space Research 65, 506-517. URL: https://doi.org/10.1016/j.asr.2019.09.045https: //linkinghub.elsevier.com/retrieve/pii/S0273117719307239, doi:10.1016/j.asr.2019.09.045.

Yeomans, C.M., Middleton, M., Shail, R.K., Grebby, S., Lusty, P.A.J., 2019. Integrated Object-Based Image Analysis for semi-automated geological lineament detection in southwest England. Computers \& Geosciences 123, 137-148 [Available Online November 2018]. URL: https://doi . org/10.1016/j.cageo.2018.11.005, doi:10.1016/j.cageo.2018.11.005. 


\section{List of Figures}

1 A) Regional overview of the study area, detailing the primary geological units in SW England B) Seafloor depth off of Hartland Point, with the rectangle highlighting an area that contains a step-change in bathymetry (reflecting a palaeocoastline) used to showcase the feature extraction methods and resulting lineament populations. Geology based upon BGS Geology 625k (DiGMapGB-625) data, with the permission of the British Geological Survey. . . . . . . . . . . . . . . . . . . . . . 25

2 Zoomed area used to showcase different feature extraction methods used in this study. A) magnitude of gradient filter; B) magnitude of Sobel filter; C) 3 x 3 Laplacian filter; D) 5 x 5 Laplacian filter; E) hillshade transform; F) tilt derivative (TDR) transform. . . . . . . . . . . . . . . . . . . . 26

3 A subset of the semi-automated lineament populations highlighting performance over the platform edge where the tilt derivative captures the most consistent lineament set. Derived from A) magnitude of gradient filter; B) magnitude of Sobel filter; C) 3 x 3 Laplacian filter; D) 5 x 5 Laplacian filter; E) hillshade transform; F) tilt derivative (TDR) transform. . . . . . . . . . . . . . . . . .

4 Kernel Density Estimate (KDE) plot for the depths at which lineaments are sensed for each method where GRAD = gradient filter; LP3 $=3 \times 3$ Laplacian; LP5 $=5 \times 5$ Laplacian; HS $=$ Hillshade and TDR $=$ tilt derivative. The TDR-derived lineament population shows a clear deviation from others where lineaments at depths $>-28 \mathrm{~m}$ are detected for this transform but not other operators. . . . . . .

5 Equal-area wedge rose diagrams for lineament populations derived from each feature extraction technique. The major NW-SE trend is apparent in all plots but with variable clarity. Plots are based on guidelines by Sanderson and Peacock (2020) . . . . . . . . . . . . . . . . . .

6 Three rose diagrams where A) is the original population of lineaments for the TDR transform; B) is the population of spurious lineaments; C) the final lineament population for the TDR transform following

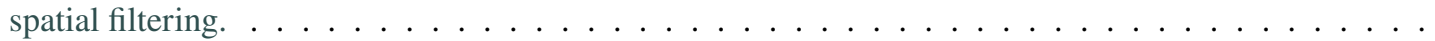


Application of the tilt derivative transform to bathymetric data

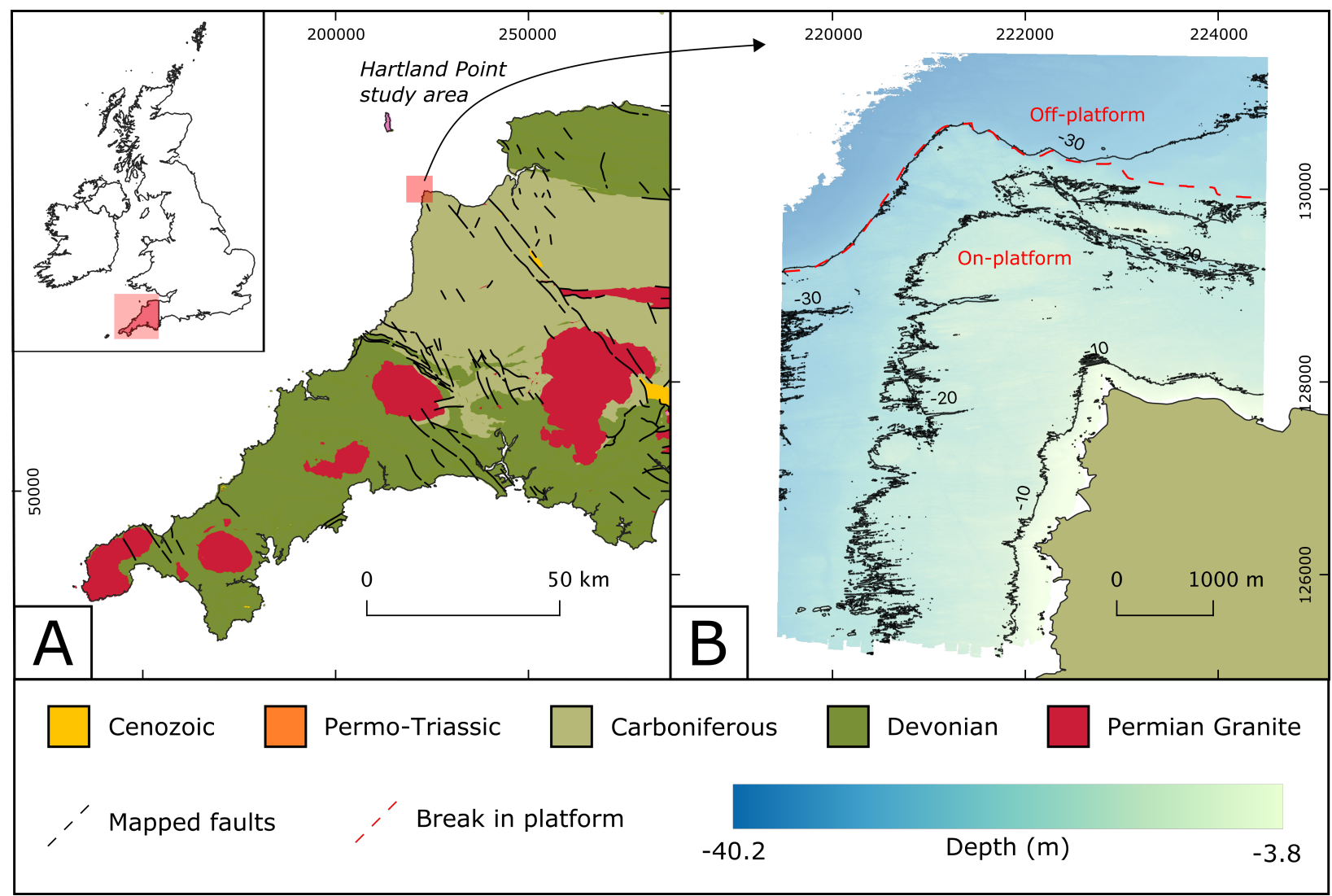

Figure 1: A) Regional overview of the study area, detailing the primary geological units in SW England B) Seafloor depth off of Hartland Point, with the rectangle highlighting an area that contains a step-change in bathymetry (reflecting a palaeocoastline) used to showcase the feature extraction methods and resulting lineament populations. Geology based upon BGS Geology 625k (DiGMapGB-625) data, with the permission of the British Geological Survey. 
Application of the tilt derivative transform to bathymetric data

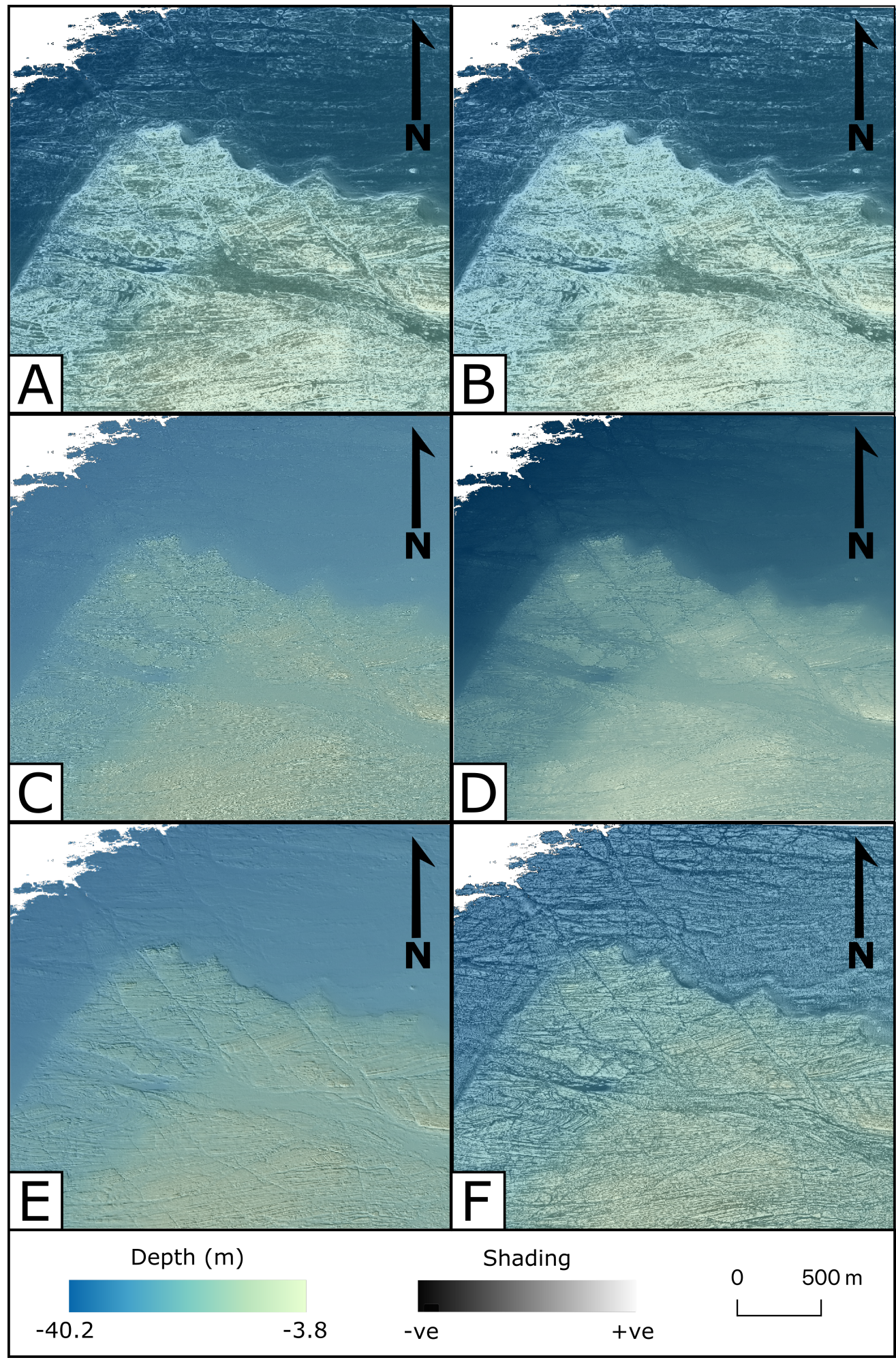

Figure 2: Zoomed area used to showcase different feature extraction methods used in this study. A) magnitude of gradient filter; B) magnitude of Sobel filter; C) $3 \times 3$ Laplacian filter; D) $5 \times 5$ Laplacian filter; E) hillshade transform; F) tilt derivative (TDR) transform. 


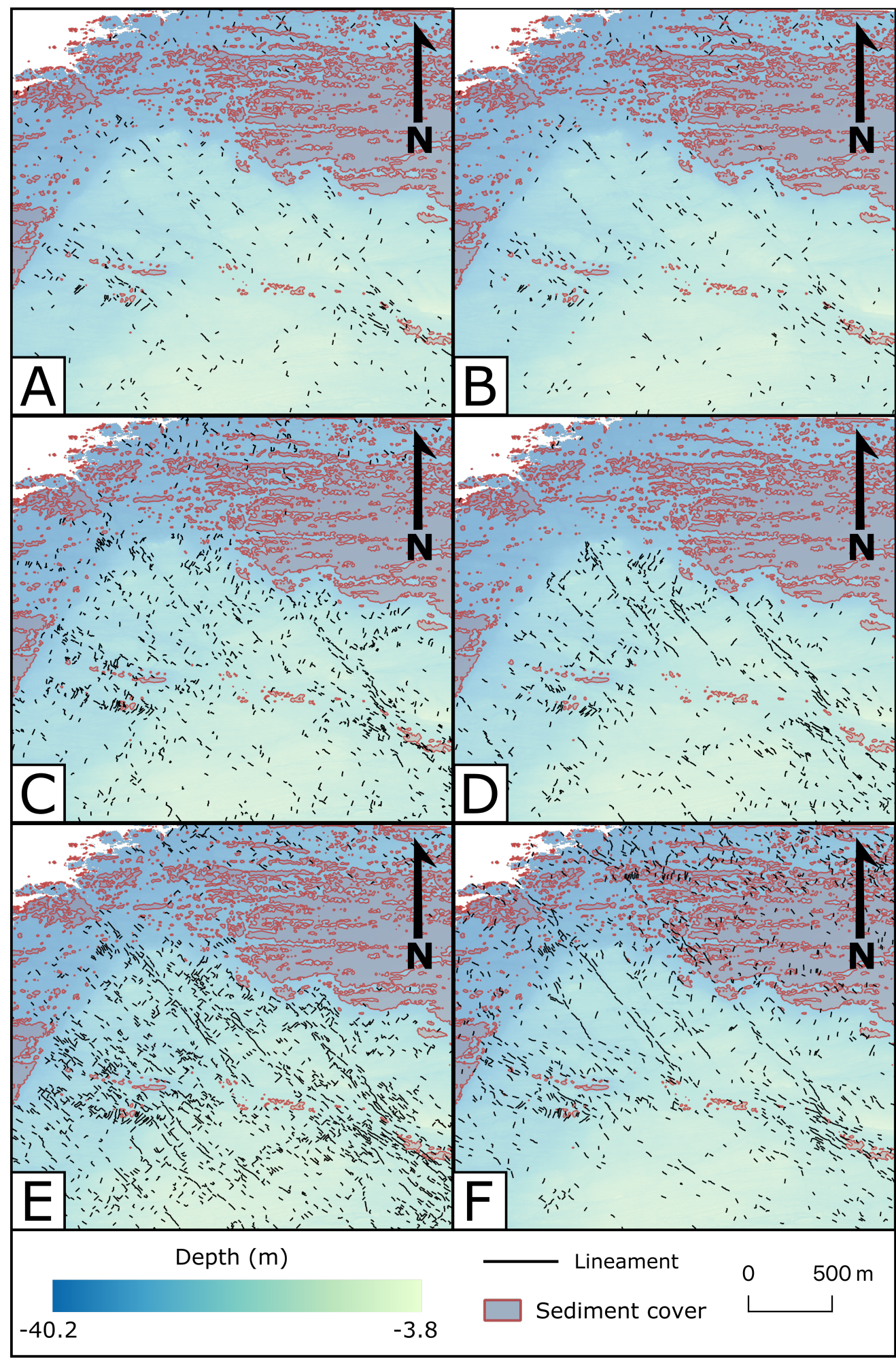

Figure 3: A subset of the semi-automated lineament populations highlighting performance over the platform edge where the tilt derivative captures the most consistent lineament set. Derived from A) magnitude of gradient filter; B) magnitude of Sobel filter; C) $3 \times 3$ Laplacian filter; D) $5 \times 5$ Laplacian filter; E) hillshade transform; F) tilt derivative (TDR) transform. 


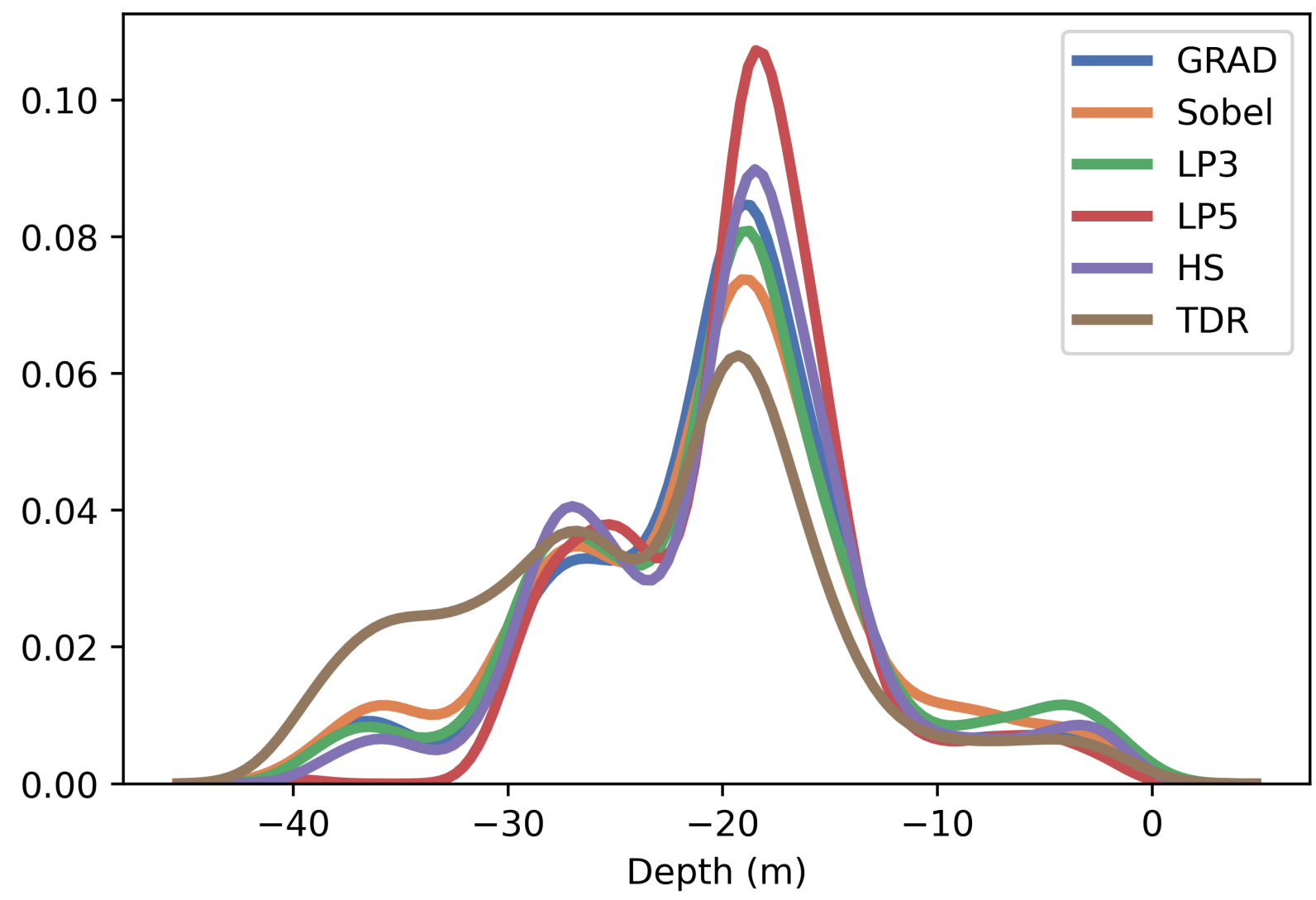

Figure 4: Kernel Density Estimate (KDE) plot for the depths at which lineaments are sensed for each method where GRAD = gradient filter; LP3 $=3 \times 3$ Laplacian; LP5 $=5 \times 5$ Laplacian; HS $=$ Hillshade and TDR = tilt derivative. The TDR-derived lineament population shows a clear deviation from others where lineaments at depths $>-28 \mathrm{~m}$ are detected for this transform but not other operators. 


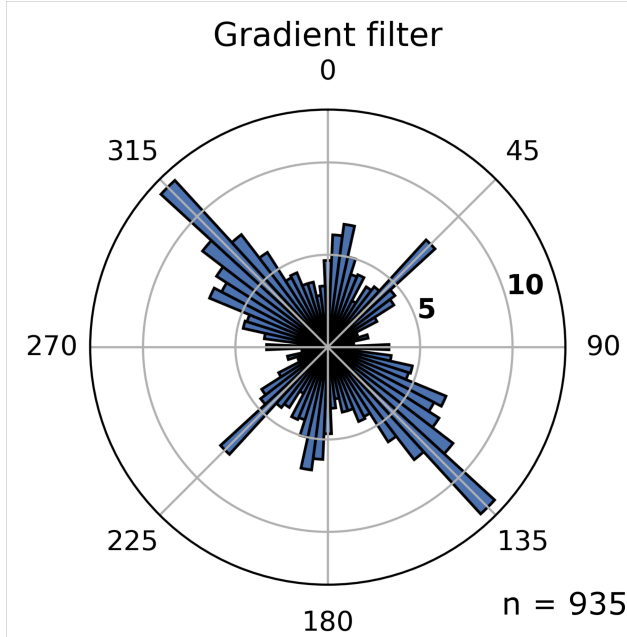

$3 \times 3$ Laplacian filter 0

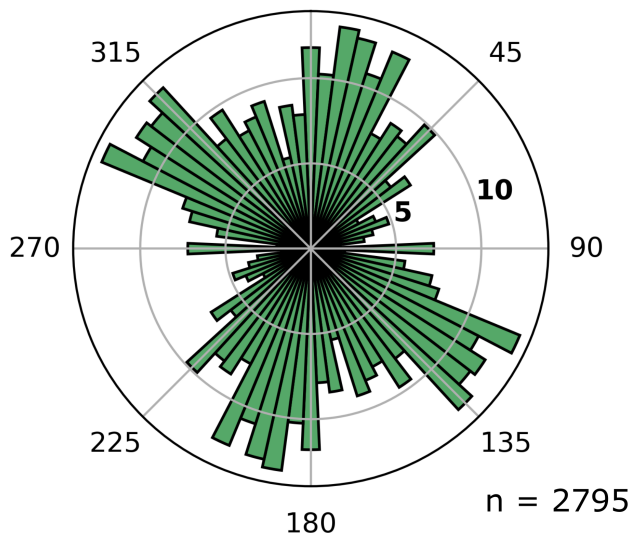

Hillshade transform 0

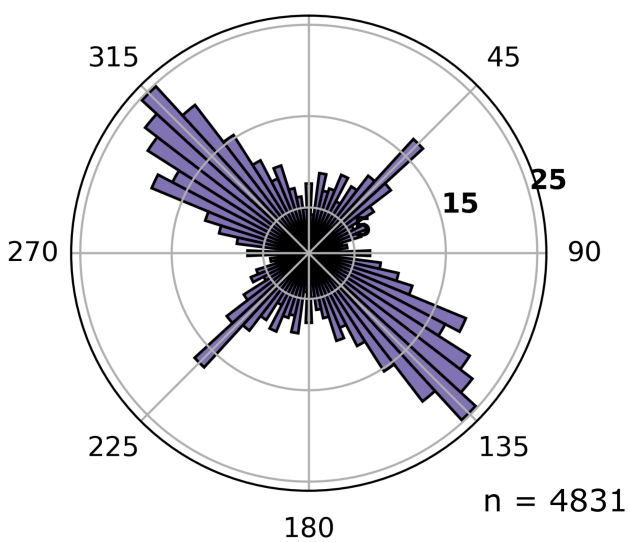

Sobel filter

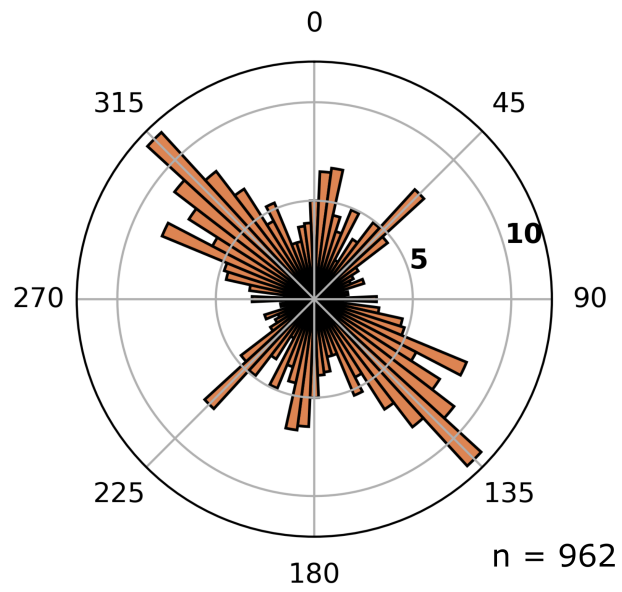

$5 \times 5$ Laplacian filter

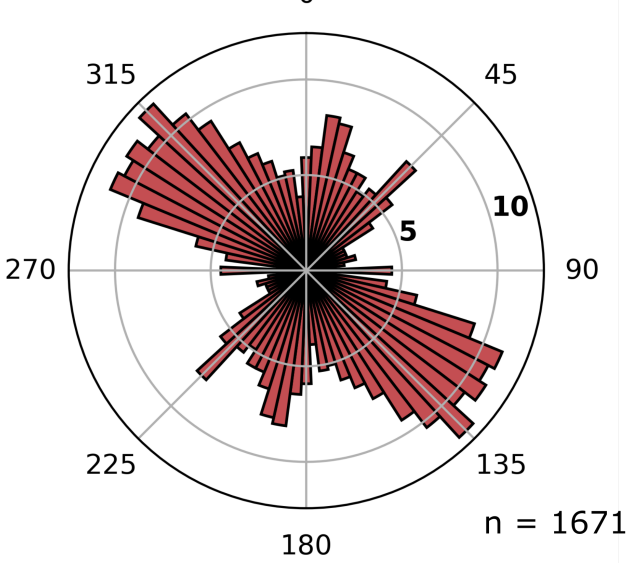

TDR transform

0

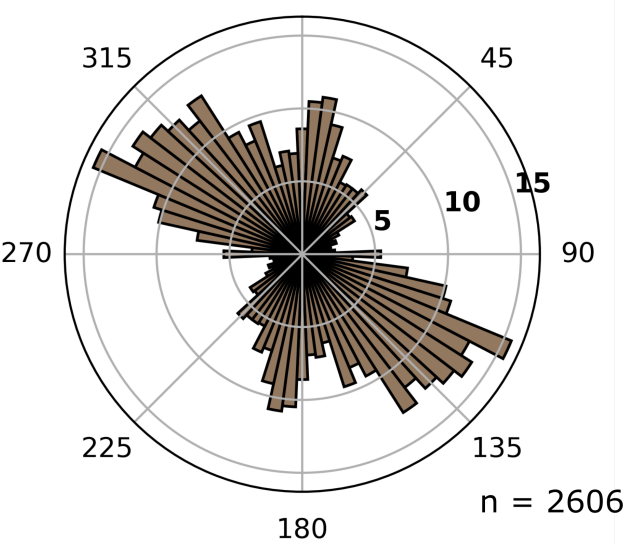

Figure 5: Equal-area wedge rose diagrams for lineament populations derived from each feature extraction technique. The major NW-SE trend is apparent in all plots but with variable clarity. Plots are based on guidelines by Sanderson and Peacock (2020). 

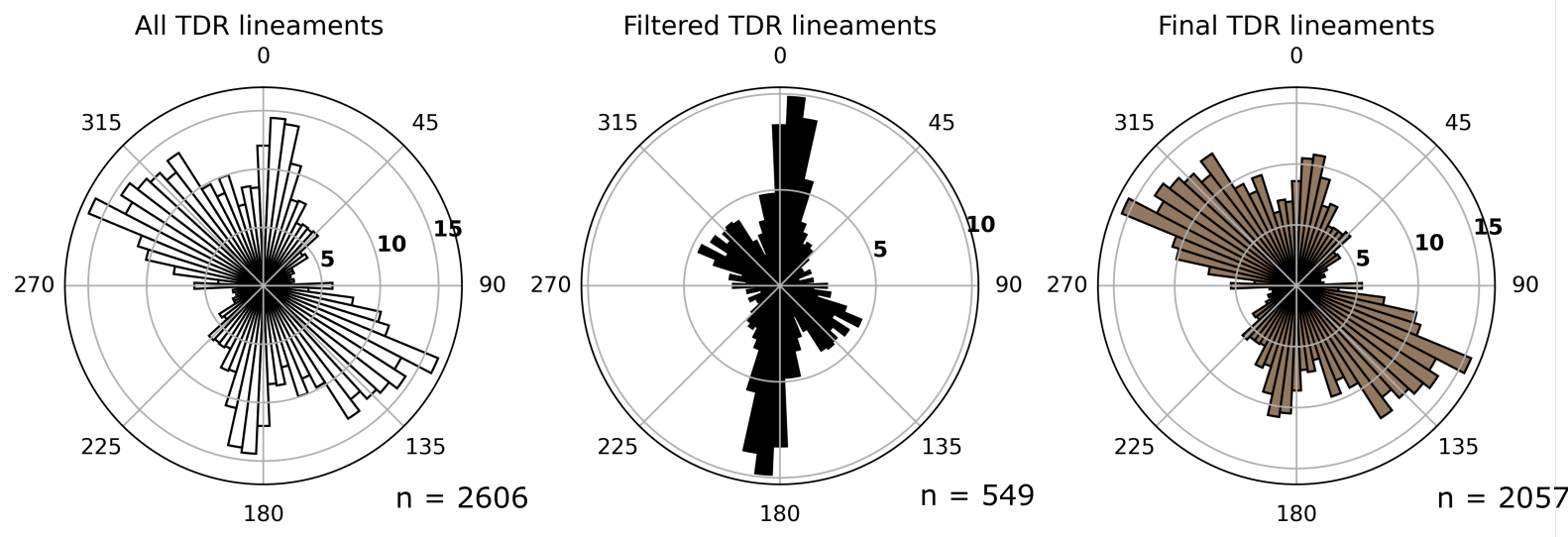

Figure 6: Three rose diagrams where A) is the original population of lineaments for the TDR transform; B) is the population of spurious lineaments; C) the final lineament population for the TDR transform following spatial filtering. 


\section{List of Tables}

1 Statistical summary of length and depth for each lineament population derived by the six different feature extraction operators (Oper.) where GRAD = gradient filter; LP3 $=3 \times 3$ Laplacian; LP5 $=5 \times$ 5 Laplacian; HS $=$ Hillshade and TDR $=$ tilt derivative. Removed lineaments include those by spatial filtering and parentheses denote those removed due to NaN values. $\mu=$ Mean, $\sigma=$ standard deviation, Skew $=$ Skewness and $\mathrm{Kurt}=$ kurtosis $\ldots \ldots \ldots \ldots \ldots \ldots \ldots \ldots \ldots$ 
Application of the tilt derivative transform to bathymetric data

\section{Table 1}

Statistical summary of length and depth for each lineament population derived by the six different feature extraction operators (Oper.) where GRAD = gradient filter; LP3 $=3 \times 3$ Laplacian; LP5 = $5 \times 5$ Laplacian; HS = Hillshade and TDR = tilt derivative. Removed lineaments include those by spatial filtering and parentheses denote those removed due to $\mathrm{NaN}$ values. $\mu=$ Mean, $\sigma=$ standard deviation, Skew $=$ Skewness and Kurt $=$ kurtosis

\begin{tabular}{llllllllll} 
Type & Oper. & $\mathbf{N}$ & Removed & $\mu$ & $\sigma$ & Median & Range & Skew & Kurt \\
\hline length & GRAD & 935 & 8 & 23.67 & 9.66 & 20.80 & 117.49 & 4.27 & 30.70 \\
length & Sobel & 962 & 6 & 22.84 & 7.54 & 20.38 & 78.37 & 2.97 & 16.38 \\
length & LP3 & 2795 & $7(1)$ & 25.14 & 10.14 & 22.07 & 96.06 & 2.46 & 9.16 \\
length & LP5 & 1671 & $0(2)$ & 28.28 & 15.50 & 23.87 & 194.03 & 4.06 & 27.33 \\
length & HS & 4831 & 0 & 29.71 & 17.98 & 24.39 & 273.62 & 4.04 & 28.36 \\
length & TDR & 2606 & $549(6)$ & 28.97 & 17.45 & 23.67 & 230.14 & 4.28 & 29.73 \\
depth & GRAD & 935 & 8 & -20.43 & 7.02 & 20.80 & 39.00 & -0.09 & 0.76 \\
depth & Sobel & 962 & 6 & -20.66 & 7.56 & 20.38 & 38.95 & -0.04 & 0.20 \\
depth & LP3 & 2795 & $7(1)$ & -20.16 & 7.54 & 22.07 & 40.49 & 0.10 & 0.34 \\
depth & LP5 & 1671 & $0(2)$ & -19.35 & 5.51 & 23.87 & 38.40 & 0.25 & 0.87 \\
depth & HS & 4831 & 0 & -20.02 & 6.81 & 24.39 & 39.65 & 0.06 & 0.60 \\
depth & TDR & 2606 & $549(6)$ & -23.37 & 8.32 & 23.67 & 39.46 & 0.09 & -0.26
\end{tabular}

